Article

\title{
Examining the Effects of $(\alpha 4) 3(\beta 2) 2$ Nicotinic Acetylcholine Receptor-Selective Positive Allosteric Modulator on Acute Thermal Nociception in Rats
}

\author{
Farah Deba ${ }^{1,2}$, Kara Ramos ${ }^{2}$, Matthew Vannoy ${ }^{2}$, Kemburli Munoz $^{2}$, Lois S. Akinola ${ }^{3}$, \\ M. Imad Damaj ${ }^{3}$ and Ayman K. Hamouda ${ }^{1,2, *}$ \\ 1 Department of Pharmaceutical Sciences, College of Pharmacy, The University of Texas at Tyler, \\ Tyler, TX 75799, USA; Fdeba@uttyler.edu \\ 2 Department of Pharmaceutical Sciences, College of Pharmacy, Texas A\&M Health Sciences Center MS 131, \\ 1010 W. Ave. B, Kingsville, TX 78363, USA; ramoskara09@yahoo.com (K.R.); \\ matthewvannoy19@gmail.com (M.V.); munozkim0903@gmail.com (K.M.) \\ 3 Department of Pharmacology and Toxicology, Medical College of Virginia, Virginia Commonwealth \\ University, Kontos Medical Science Building, 1217 E. Marshall St., P.O. Box 980613, Richmond, \\ VA 23298, USA; akinolals@vcu.edu (L.S.A.); m.damaj@vcuhealth.org (M.I.D.) \\ * Correspondence: Ahamouda@uttyler.edu; Tel.: +1-903-565-6578
}

Received: 4 June 2020; Accepted: 22 June 2020; Published: 25 June 2020

\begin{abstract}
Neuronal nicotinic acetylcholine receptor (nAChR)-based therapeutics are sought as a potential alternative strategy to opioids for pain management. In this study, we examine the antinociceptive effects of 3-(2-chlorophenyl)-5-(5-methyl-1-(piperidin-4-yl)-1H-pyrazol-4-yl)isoxazole (CMPI), a novel positive allosteric modulator (PAM), with preferential selectivity to the low agonist sensitivity $(\alpha 4) 3(\beta 2) 2 \mathrm{nAChR}$ and desformylflustrabromine ( $\mathrm{dFBr}$ ), a PAM for $\alpha 4$-containing nAChRs. We used hot plate and tail flick tests to measure the effect of $\mathrm{dFBr}$ and CMPI on the latency to acute thermal nociceptive responses in rats. Intraperitoneal injection of dFBr, but not CMPI, dose-dependently increased latency in the hot plate test. In the tail flick test, the effect achieved at the highest $\mathrm{dFBr}$ or CMPI dose tested was only $<20 \%$ of the maximum possible effects reported for nicotine and other nicotinic agonists. Moreover, the coadministration of $\mathrm{dFBr}$ did not enhance the antinociceptive effect of a low dose of nicotine. Our results show that the direct acute effect of dFBr is superior to that for CMPI, indicating that selectivity to $(\alpha 4) 3(\beta 2) 2 \mathrm{nAChR}$ is not advantageous in alleviating responses to acute thermal nociceptive stimulus. However, further studies are necessary to test the suitability of $(\alpha 4) 3(\beta 2) 2$ nAChR-selective PAMs in chronic pain models.
\end{abstract}

Keywords: nicotinic acetylcholine receptors (nAChRs); positive allosteric modulators (PAMs); desformylflustrabromine (dFBr); CMPI; acute thermal nociception; hot plate; tail flick

\section{Introduction}

Neuronal nicotinic acetylcholine receptors (nAChRs) containing the $\alpha 4$ and $\beta 2 \mathrm{nAChR}$ subunits (herein referred to as $\alpha 4 \beta 2^{*}$ nAChRs with asterisks, to indicate the diversity of subunit composition) are the most predominant nAChR subtypes in the brain [1-3]. The $\alpha 4 \beta 2^{*} \mathrm{nAChRs}$ are expressed in neuronal circuitries involved in the transmission, perception, and modulation of painful stimuli and contribute to the underlying pathophysiological processes of neuropathic and inflammatory pain [4-6]. Compounds targeting the $\alpha 4 \beta 2^{*} n A C h R s$ hold promise in the development of non-opioid analgesics [6-9]. The antinociceptive efficacy of $\alpha 4 \beta 2^{*}$ nAChRs agonists has been demonstrated in animal models, including those for acute thermal pain, neuropathic pain, pain associated with inflammatory conditions, and chemotherapy-induced painful neuropathy [10-13]. The development 
of clinically relevant nicotinic agonists was proven difficult, despite their potent antinociceptive and anti-inflammatory effects in a variety of preclinical models. Doses of nAChR agonists that produced analgesic effects also produced side effects, due to interactions at other nAChRs subtypes (e.g., $\alpha 3$-containing nAChRs) $[14,15]$. Therefore, the positive allosteric modulator (PAM) of nAChRs emerged as a class of therapeutic agents to overcome the pharmacological selectivity and safety issues associated with agonists [16-21].

By definition, PAMs of $\mathrm{nAChR}$ bind at allosteric sites other than the agonist binding sites. Therefore, they do not replace the agonist nor directly activate the nAChR channel on their own. Instead, they bind simultaneously with an agonist, increasing its potency, efficacy, or both, which results in the enhancement of nAChR function [22]. As such, PAMs avoid two unwanted pharmacological properties seen with nAChR agonists: 1) binding at ACh binding sites which are highly conserved among multiple nAChR subtypes, resulting in unwanted side effects [8]; and 2) changes in nAChRs dynamics (e.g., continuous activation and desensitization) which can result in unwanted effects on the pattern of cholinergic neuronal activities [16]. In in vitro studies, many nAChR PAMs have exhibited a higher degree of nAChR subtype selectivity than agonists [23-25]. In in vivo studies, PAMs of nAChRs have antinociceptive and anti-inflammatory effects of their own and improve the analgesic effects, without increasing side effects when coadministered with $\alpha 4 \beta 2 \mathrm{nAChR}$ agonists $[4,15,26-28]$.

The two $\alpha 4 \beta 2^{*} \mathrm{nAChR}$ isoforms, the low agonist sensitivity isoform $((\alpha 4) 3(\beta 2) 2) \mathrm{nAChR}$ comprised of three alpha and two beta subunits) and the high agonist sensitivity isoform $((\alpha 4) 2(\beta 2) 3 \mathrm{nAChR}$ comprised of two alpha and three beta subunits), differ in their biochemical and pharmacological characteristics and potentially differ in their in vivo expression patterns and their roles in different central nervous system functions $[3,29,30]$. Therefore, we reasoned that nAChR PAM subtype selectivity $((\alpha 4) 3(\beta 2) 2 \mathrm{vs}$. $(\alpha 4) 2(\beta 2) 3 \mathrm{nAChR}$ ) would translate to differences in the in vivo efficacy. In this study, we examine the antinociceptive effects of 3-(2-chlorophenyl)-5-(5-methyl-1-(piperidin-4-yl)-1H-pyrazol-4-yl)isoxazole (CMPI) [24], a PAM with a unique selectivity to the low agonist sensitivity $(\alpha 4) 3(\beta 2) 2$ $\mathrm{nAChR}[24,31,32]$ and the results were compared with those obtained with $\mathrm{dFBr}$ (desformylflustrabromine, $\mathrm{N}$-(2-[6-bromo-2(1,1-dimethyl-2-propyl)-1H-indol-3-yl]ethyl-N-methylamine), a PAM of $\alpha 4$-containing nAChRs (Figure 1) $[23,33,34]$. We used hot plate and tail flick tests for acute thermal nociception as two well-established paradigms in which the $\alpha 4 \beta 2^{*} \mathrm{nAChRs}$ play an essential role. Our results show that the direct acute effect of CMPI on latency to acute thermal stimuli is minimal, and not comparable to that seen with non-selective $n A C h R$ agonists, like nicotine, or with PAMs with broader $n A C h R$ subtype coverage, like dFBr. These results indicate that selectivity to $(\alpha 4) 3(\beta 2) 2 \mathrm{nAChR}$ may not be advantageous in treating acute pain conditions. However, these results do not preclude their potential suitability for the treatment of chronic pain conditions, and further studies are warranted to test the antinociceptive and anti-allodynic effect of CMPI in models for neuropathic and inflammatory pain.
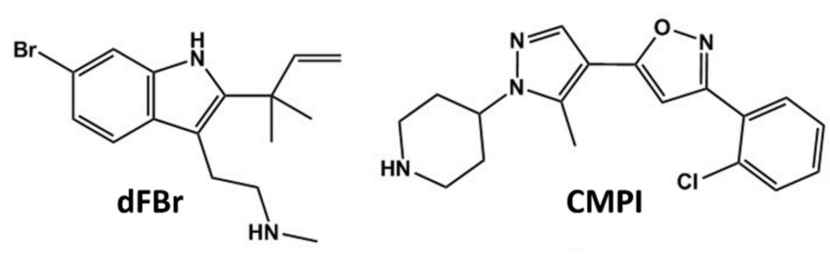

Figure 1. Structures of $\alpha 4 \beta 2^{*}$ neuronal nicotinic acetylcholine receptors (nAChRs) positive allosteric modulators (PAMs), desformylflustrabromine (dFBr) and 3-(2-chlorophenyl)-5-(5-methyl-1-(piperidin -4-yl)-1H-pyrazol-4-yl)isoxazole (CMPI).

\section{Results}

\subsection{Effect of dFBr and CMPI on Acute Thermal Nociception Behavior in Hot Plate Test}

The acute thermal pain latency before and after intraperitoneal (i.p.) injection of vehicle (a mixture of $90 \%$ saline, $5 \%$ Tween 80 , and $5 \%$ propylene glycol), dFBr $(5,10$, or $20 \mathrm{mg} / \mathrm{kg})$, or CMPI $(2,5,10$, 
15 , or $20 \mathrm{mg} / \mathrm{kg}$ ) on Sprague-Dawley rats in the hot plate test was determined using a Hot Plate Analgesia Meter (IITC Inc.) maintained at $55^{\circ} \mathrm{C}$. Figure $2 \mathrm{~A}, \mathrm{~B}$ show the time course of $\mathrm{dFBr}$ and CMPI effects, respectively, on acute pain latency in the hot plate test, expressed as a percentage of the maximum possible effect (MPE \%). Following i.p. injection, dFBr dose-dependently increased the latency (time for hind paw-licking behavior) in the hot plate test. A fast onset characterized the dFBr effect; effect starts within $15 \mathrm{~min}$, and the maximum effect was achieved within 30 min posttreatment. The time course of $\mathrm{dFBr}$ dose-response was statistically significant in two-way ANOVA ( $\mathrm{F}_{\mathrm{dFBr}}$ dosexTime $(15,228)=24.17, p<0.0001)$. The effect of $\mathrm{dFBr}$ was reversible, and the hot plate thermal latenare shown cy returned to within $\pm 5 \%$ of pretreatment baseline latency after $180 \mathrm{~min}$. In contrast, the effect of CMPI on hot plate thermal latency was less than 10\% of MPE at all CMPI doses tested (Figure 1B). The time course of CMPI dose-response was much less significant in two-way ANOVA $\left(F_{\text {CMPI dosexTime }}(20,348)=1.737, p=0.0264\right)$ than dFBr. At 30 min following treatment, dFBr at 5, 10, and $20 \mathrm{mg} / \mathrm{kg}$ produced a statistically significant effect $(p<0.0001)$ when compared with vehicle using Holm-Sidak's multiple comparison test (Figure 2C). The effect of dFBr at 10 and $20 \mathrm{mg} / \mathrm{kg}$ was statistically significant $(p<0.0001)$ compared with pretreatment with an equivalent dose of CMPI. CMPI at 5,10 , and $20 \mathrm{mg} / \mathrm{kg}$ was also significant when compared with the vehicle with $p$ values of $0.0041,0.0026$, and 0.0711 , respectively.
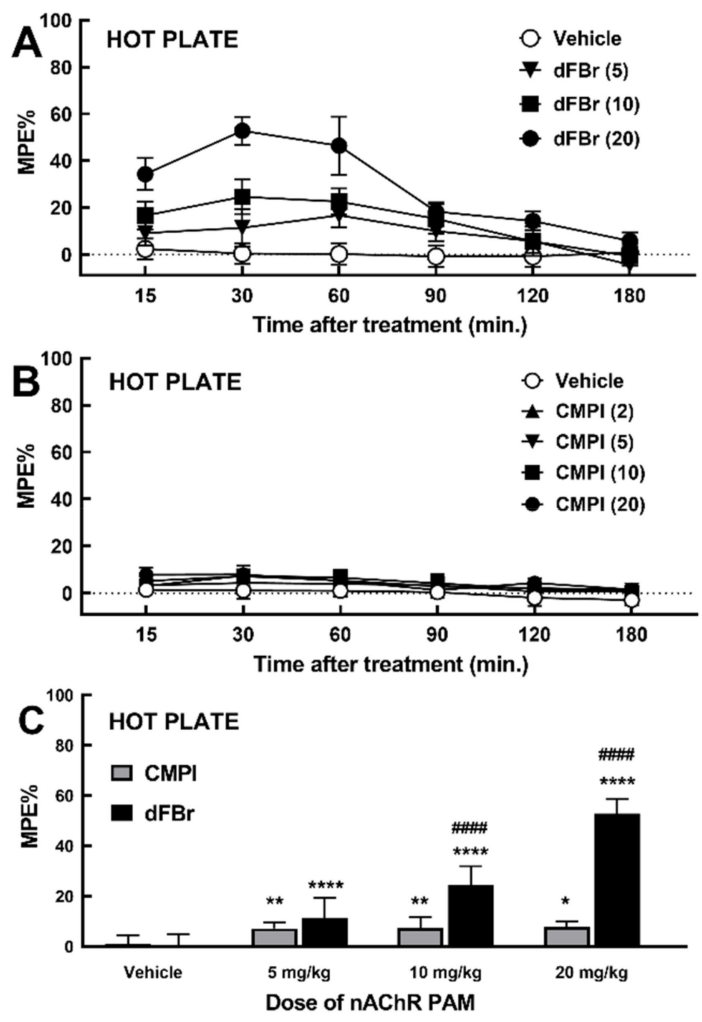

Figure 2. (A,B) Time course of the effects of $\mathrm{dFBr}$ and CMPI, respectively, on acute thermal nociception in the hot plate test. Rats received i.p. injection of vehicle or increasing dose (in $\mathrm{mg} / \mathrm{kg}$ ) of $\mathrm{dFBr}$ or CMPI, then subjected to the hot plate at the time indicated. Data are shown as mean $\% \mathrm{MPE} \pm \mathrm{SD}$ of at least six rats per each treatment group, as detailed under Materials and Methods (Section 4.3.1). (C) Peak dFBr and CMPI effect at 30 min post-injection were analyzed using two-way ANOVA with Holm-Sidak's multiple comparisons test. ${ }^{*} p<0.05,{ }^{* *} p<0.01,{ }^{* * *} p<0.001,{ }^{* * * *} p<0.0001$ indicates statistical significance between drug treatment versus vehicle group. \#\#\# $p<0.0001$ indicates the significant difference between $\mathrm{dFBr}$ treatment versus treatment with the same dose of CMPI. 


\subsection{Effect of $\mathrm{AFBr}$ and CMPI on Acute Thermal Nociception Behavior in Tail Flick Test}

The time course of the acute thermal pain latency of Sprague-Dawley rats in tail flick measured following the i.p. injection of the vehicle, $\operatorname{dFBr}(5,10$, or $20 \mathrm{mg} / \mathrm{kg})$, or CMPI $(2,5,10,15$, or $20 \mathrm{mg} / \mathrm{kg})$ are shown in Figure 3A,B. The effect of dFBr and CMPI on tail flick thermal latency was less than $20 \%$ of MPE at all CMPI and dFBr doses tested. Statistical analyses of dose-dependent effect of dFBr and CMPI at 30 min following treatment using two-way ANOVA with Holm-Sidak's multiple comparison test (Figure $3 \mathrm{C}$ ) revealed a statistically significant $(p>0.001)$ difference between pretreatment with $10 \mathrm{mg} / \mathrm{kg}$ of $\mathrm{dFBr}$ or CMPI and vehicle pretreatment. There was no statistical significance $(p>0.05)$ between $\mathrm{dFBr}$ treatments versus treatment with equivalent doses of CMPI.
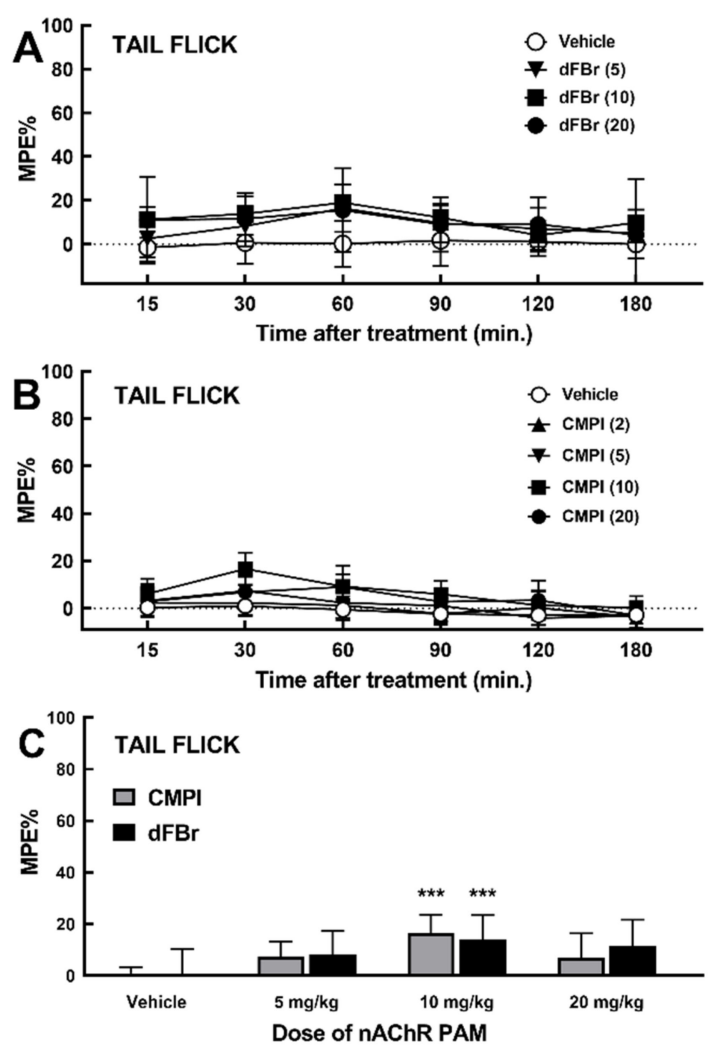

Figure 3. (A,B) Time course of the effects of increasing dose of dFBr and CMPI, respectively, on acute thermal nociception in the tail flick test. Rats were pretreated with i.p. injection of vehicle, $\mathrm{dFBr}(5$, 10 , or $20 \mathrm{mg} / \mathrm{kg})$ or CMPI $(5,10$, or $20 \mathrm{mg} / \mathrm{kg})$, then subjected to the tail flick after $15,30,60,90$, 120 , and $180 \mathrm{~min}$. Data are shown as mean $\% \mathrm{MPE} \pm \mathrm{SD}$ of at least six rats per each treatment group, as detailed under Materials and Methods (Section 4.3.2). (C) Peak dFBr and CMPI effect at $30 \mathrm{~min}$ post-injection were analyzed using two-way ANOVA with Holm-Sidak's multiple comparisons test. *** $p<0.001$ indicates a significant difference between drug treatment versus vehicle.

\subsection{Effect of dFBr on Nicotine-Induced Acute Thermal Antinociception}

To examine the effect of $\mathrm{dFBr}$ in combination with a low dose of nicotine on acute thermal nociception, rats were treated with nicotine $(0.5 \mathrm{mg} / \mathrm{kg}$, s.c.), with or without treatment with $\mathrm{dFBr}(5 \mathrm{or}$ $10 \mathrm{mg} / \mathrm{kg}$, i.p. injection), then subjected to the hot plate and tail flick tests (Figure 4). 

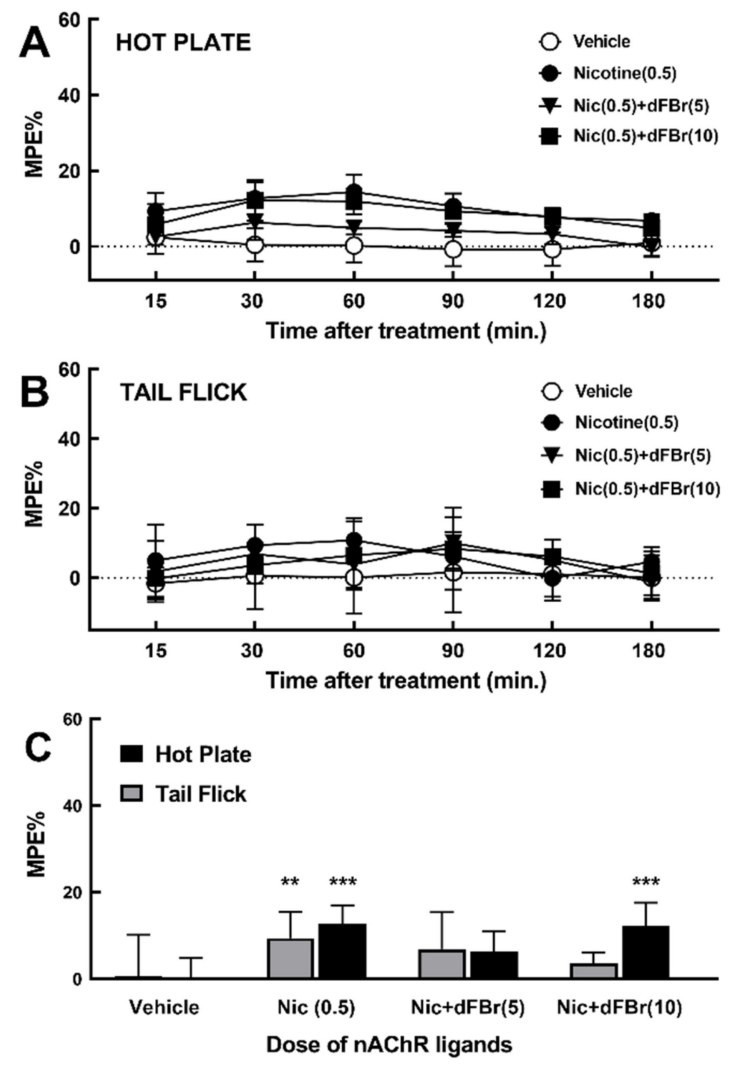

Figure 4. (A and B) Time course of the effects of dFBr on nicotine-induced acute thermal antinociception in the hot plate and tail flick tests, respectively. Rats were pretreated with i.p. injection of vehicle or $\mathrm{dFBr}$ then with s.c. injection of $0.5 \mathrm{mg} / \mathrm{kg}$ nicotine, then subjected to the hot plate or tail flick at 15,30 , $60,90,120$, and $180 \mathrm{~min}$. Data are shown as mean $\% \mathrm{MPE} \pm \mathrm{SD}$ of at least six rats per each treatment group, as detailed under Materials and Methods (Section 4.3.2). (C) Peak effect at 30 min post-injection were analyzed using two-way ANOVA with Holm-Sidak's multiple comparisons test. ${ }^{* *} p<0.01$ and ${ }^{* * *} p<0.001$ indicate significant difference between drug treatment versus vehicle group. $\mathrm{dFBr}$ treatments versus treatment with nicotine alone were not statistically significant $(p>0.05)$.

Pretreatment with nicotine at $0.5 \mathrm{mg} / \mathrm{kg}$ enhanced acute thermal pain latency with \%MPE of $13 \pm 2$ and $10 \pm 2 \%$, in hot plate and tail flick tests. These values are consistent with previously reported values for low doses of nicotine [35]. The coadministration of dFBr with nicotine did not enhance the nicotine-induced acute thermal antinociceptive effect in the hot plate or tail flick tests. Instead, the coadministration of $\mathrm{dFBr}$ produced a dose-dependent decrease in nicotine-induced antinociceptive effect on tail flick test, and at $5 \mathrm{mg} / \mathrm{kg}$, reduced the nicotine-induced antinociceptive effect in the hot plate test. Analyses of these results using two-way ANOVA with Holm-Sidak's multiple comparison test (Figure $4 \mathrm{C}$ ) revealed that the effect of nicotine alone was statistically significant from vehicle pretreatment $(p<0.001$ and $p<0.01$ in hot plate and tail flick, respectively). There were no statistically significant differences between the effect of nicotine $+\mathrm{dFBr}$ treatments when compared to nicotine pretreatment.

\subsection{Rat Sex Does Not Influence dFBr and CMPI Modulation of Acute Thermal Nociception}

To investigate if there was a sex difference in $\mathrm{dFBr}$ or CMPI effects in acute thermal nociception tests, \%MPE values were calculated separately for males and females within treatment groups (Figure 5), based on latency recorded in hot plate and tail flick 30 min following the i.p. injection of $\mathrm{dFBr}(5,10$, or $20 \mathrm{mg} / \mathrm{kg}$ ) or CMPI (5 or $10 \mathrm{mg} / \mathrm{kg}$ ) (experiments shown in Figures 1 and 2). Two-way ANOVA 
analyses comparing male versus female to same-drug treatment response revealed no significant difference $(p>0.05)$ due to animal sex.

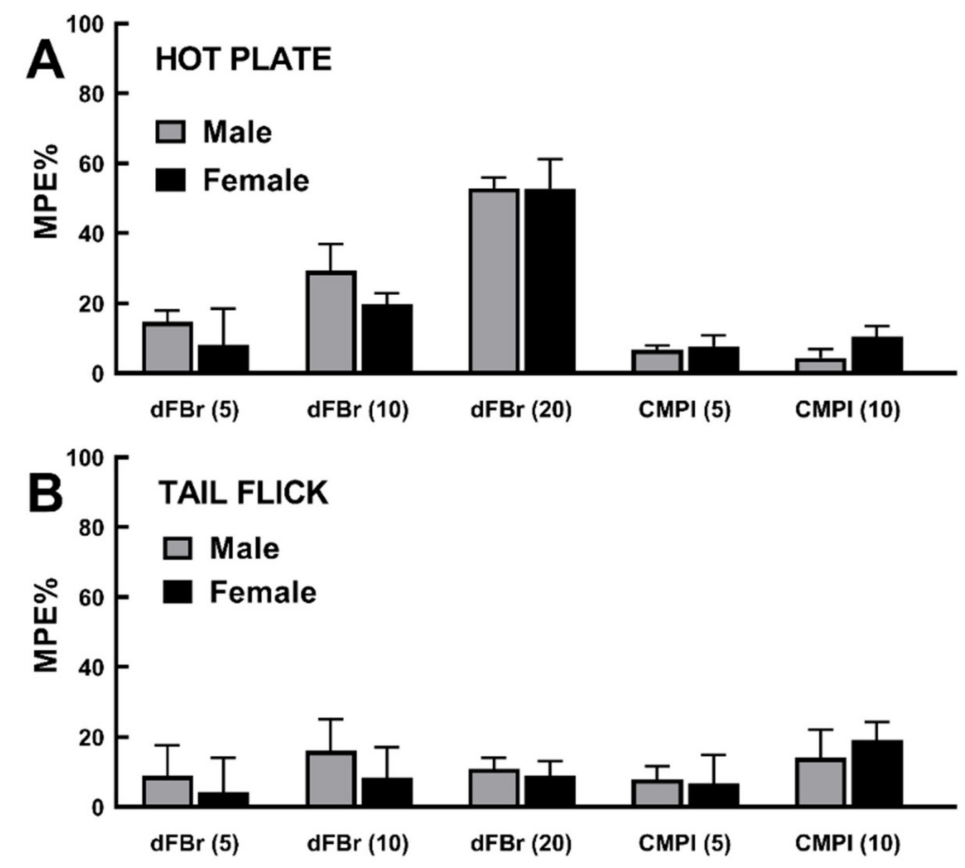

Figure 5. (A) Effect of rat sex on latency (\%MPE + SD) to acute thermal nociception in the Hot Plate test (experiments in Figure 1), recorded 30 min following i.p. injection of dFBr or CMPI (dose indicated in $\mathrm{mg} / \mathrm{kg}$ rat weight). (B) Effect of rat sex on latency (\%MPE + SD) to acute thermal nociception in the Tail Flick test (experiments in Figure 2) recorded 30 min following i.p. injection of dFBr or CMPI. Data are non-significant $(p>0.05)$ based on two-way ANOVA analyses with Holm-Sidak's multiple comparison test.

\section{Discussion}

The role of neuronal $\mathrm{nAChRs}$ as possible targets for modulation of nociception and the pathophysiology of chronic pain has been established in many animal and human studies $[4,6,8]$. The ability of $\alpha 4 \beta 2 *$ nAChR agonists, including epibatidine, nicotine, A-85380, and ABT-594, to reduce nociceptive responses has been demonstrated in a variety of rodent pain models [6,9]. Furthermore, PAMs of $\alpha 4 \beta 2^{*} \mathrm{nAChR}$ reduced nociceptive responses in animal models of neuropathic and chemically-induced pain $[27,28]$. In this study, we investigated the effects of two nAChR PAMs, $\mathrm{dFBr}$ and CMPI, in acute thermal pain tests. $\mathrm{dFBr}$ is a tryptophan-derived metabolite isolated from the North Sea bryozoan Flustra foliacea and found to potentiate ACh-induced responses of $\alpha 4 \beta 2^{*}$ nAChRs $[23,33]$. CMPI is a piperidine derivative that has been identified via chemical synthesis and high throughput screening as a nAChR PAM [24] then found to selectively potentiate ACh-induced responses of the low agonist sensitivity $(\alpha 4) 3(\beta 2) 2 \mathrm{nAChR}$, but not the high agonist sensitivity $(\alpha 4) 2(\beta 2) 3 \mathrm{nAChR}[31,32]$. While studies to evaluate the in vivo effects of CMPI are still in their infancy, the pharmacological effects of $\mathrm{dFBr}$ have been examined in rodent models for nicotine self-administration, nicotine withdrawal, nicotine discriminative stimulus, neuropathic pain, chemically-induced pain, and obsessive-compulsive behavior [27,28,36-39].

In this study, we begin to assess the in vivo antinociceptive efficacy of CMPI, as one of the most selective $\mathrm{nAChR}$ PAMs identified. We compare CMPI and $\mathrm{dFBr}$ ability to alleviate acute thermal pain in male and female adult Sprague-Dawley rats, using the tail-flick and hot-plate tests. These tests are extensively used to determine the antinociceptive effectiveness of drugs and believed to be mediated by nociceptive responses at spinal and supraspinal levels [40,41]. Our results, shown in Figure 2, established that $\mathrm{dFBr}$ is more effective than CMPI in reducing the hot plate test's acute thermal 
nociception. Pretreatment with dFBr increased acute thermal pain latency by 53\% MPE, whereas CMPI up to $20 \mathrm{mg} / \mathrm{kg}$ only increased acute thermal latency by $<8 \% \mathrm{MPE}$. Unlike CMPI, the effect of dFBr was dose-dependent and statistically significant $(\mathrm{P}<0.0001)$, compared to vehicle pretreatment. The effect of $\mathrm{dFBr}$ was also statistically significant $(\mathrm{P}<0.0001)$, when compared to pretreatment with an equal dose of CMPI. However, the tail flick test results, shown in Figure 3, indicate that dFBr is less effective in the tail flick than the hot plate test, whereas $\mathrm{dFBr}$ only reduced acute thermal nociception to a similar level as CMPI (15 and 17\%, respectively). Despite its direct effect in the hot plate test, dFBr did not enhance the nicotine-induced acute thermal antinociceptive effect in the hot plate or tail flick test results shown in Figure 4. The different effects of dFBr in tail flick versus hot plate tests are not surprising, because different responses in these tests have been previously reported for antinociceptives. For example, Langerman et al. have reported a higher effect of the same dose of morphine in the tail flick than the hot plate test [41]. Dissimilar effects of nAChR PAMs in the tail flick versus hot plate tests could also be attributed to the fact that different sites of the central nervous system mediate the response of these tests. The tail flick and hot plate tests are believed to be mediated via spinal and supraspinal responses, respectively [41].

The $\alpha 4 \beta 2^{*} \mathrm{nAChR}$ activity of $\mathrm{dFBr}$ and CMPI could also contribute to the differences observed in the hot plate and tail flick tests. Both $\mathrm{dFBr}$ and CMPI potentiate the low agonist sensitivity $(\alpha 4) 3(\beta 2) 2 \mathrm{nAChR}$ responses with similar potency $\left(E C_{50} \mathrm{~s} \sim 0.3 \mu \mathrm{M}\right)$ and efficacy $(\sim 400 \%$ at $1 \mu \mathrm{M})$ [31]. Nevertheless, dFBr and CMPI differ in all other pharmacological aspects tested so far, including the ability to potentiate the high agonist sensitivity $(\alpha 4) 2(\beta 2) 3 \mathrm{nAChR}[33,42]$, the location of their binding sites in the $\alpha 4 \beta 2^{*} \mathrm{nAChR}[32,34,43]$, effects on potency and efficacy of ACh dose-response curve [31,42], and the ability to penetrate the blood-brain barrier [24,36]. These differences contribute to the higher $\mathrm{dFBr}$ effect on acute thermal latency than CMPI observed in the hot plate test. Alternatively, the higher effect of dFBr can be due to differences in the nAChR subtypes involved in thermal nociception. A simple interpretation would be that the $(\alpha 4) 3(\beta 2) 2 \mathrm{nAChR}$ contributes differently to spinal and supraspinal thermal nociceptive responses. Studies using $\alpha 4$ or $\beta 2 \mathrm{nAChR}$ subunit null mutant (gene knockout) mice have suggested a more prominent role for $\alpha 4 \beta 2^{*} \mathrm{nAChR}$ in nicotine-induced antinociception in the hot-plate test, compared to the tail-flick assay [11]. More elaborate studies are required to examine this possibility. The lack of CMPI effect on the hot plate and tail flick tests was not a result of motor function impairment that is caused by CMPI treatment. The ability of rats to maintain balance on the rotating textured drum of a RotaRod (at 10 rotation per min in IITC life Science model\#755) tested $60 \mathrm{~min}$ after treatment with 5 or $10 \mathrm{mg} / \mathrm{kg}$ CMPI was not different from the vehicle treated group or from pretreatment values (data not shown).

PAMs of nAChRs, alone or added to low doses of an agonist, potentially provide a better alternative strategy to $\mathrm{nAChR}$ agonists in replacing opioids for the treatment of pain. They exhibited antinociceptive effects on their own and enhanced analgesic effects without enhancing side effects when coadministered with agonists $[15,26]$. Here, we have shown that a nAChR PAM with a broader $\alpha 4-n A C h R$ subtypes spectrum would be more advantageous than a selective $(\alpha 4) 3(\beta 2) 2$ nAChR PAM in treating acute pain conditions. Still, PAMs acting on the $(\alpha 4) 3(\beta 2) 2 \mathrm{nAChR}$ provide a considerable selectivity that potentially limits the side effects, due to binding at other $n A C h R$ subtypes. More studies are required to understand the expression and functions of $(\alpha 4) 3(\beta 2) 2 \mathrm{nAChR}$ and to examine the merit of $(\alpha 4) 3(\beta 2) 2 \mathrm{nAChR}$-selective PAMs in chronic pain models and other pathologies involving the nAChRs.

\section{Materials and Methods}

\subsection{Animals}

All animal procedures described in this study were performed using a protocol approved by the institutional animal care and use committee (IACUC) of The Texas A\&M Health Science Center-Institute of Biotechnology. Sprague-Dawley rats (150-300g; males and females) were purchased from Envigo 
and housed at an Assessment and Accreditation of Laboratory Animal Care (AAALAC, Frederick, MD USA)-accredited facility, under standard environmental conditions (food/water ad libitum, $12 \mathrm{~h}$ light/dark-light cycle, RT $24^{\circ} \mathrm{C}$ ).

\subsection{Drugs}

The dFBr, CMPI, and nicotine were purchased from Tocris Bioscience (Minneapolis, MN, USA). Tween 80, propylene glycol, and normal saline $(0.9 \% \mathrm{NaCl})$ were purchased from Acros Organic (part of Thermo Fisher Scientific, NJ), Amresco (Solon, OH.), and BDHR VWR analytical (Radnor, PA), respectively. For i.p. injection, CMPI and dFBr were dissolved in a vehicle mixture consisting of saline, Tween 80 , and propylene glycol, at a ratio of 18:1:1, respectively [38]. For s.c. injection, nicotine was dissolved in physiological saline.

\subsection{Acute Thermal Nociceptive Tests}

Latency to acute thermal nociceptive stimulus in Sprague-Dawley rats was measured using hot-plate and tail flick tests using previously established procedures [44]. Rats were acclimatized to the test room for at least $30 \mathrm{~min}$, and 2-4 control baseline acute thermal pain latencies 15-30 min apart were recorded. At least 15 min after the last baseline recording, rats were treated with an i.p. injection of vehicle or specified doses of $\mathrm{nAChR}$ ligands, and the latencies to acute thermal pain reaction were recorded at 15, 30, 60, 90, 120, and $180 \mathrm{~min}$ after injection. Vehicle was injected at a dose equal to $1 \mu \mathrm{l}$ per $\mathrm{kg}$ of rat weight, and doses of $\mathrm{nAChR}$ ligands were determined as mg per $\mathrm{kg}$ of rat weight and dissolved in a volume of vehicle equal to $1 \mu \mathrm{l} \mathrm{per} \mathrm{kg}$ of rat body weight. All experiments were performed during the light cycle. Experimenters were blind to treatment used at the time they performed the hot plate and tail flick test. Rats exhibiting signs of locomotor deficiency in the RotaRod test, enhanced thermal pain sensitivity, or abnormal coloration in tail or paws, were excluded from further testing.

\subsubsection{Hot Plate Test}

Hot plate tests were performed at a temperature of $55{ }^{\circ} \mathrm{C}$ using Hot Plate Analgesia Meter (IITC Inc.) Rat reaction time (latency to acute thermal pain in seconds) was recorded as time elapsed after placing on the hot plate metal surface until rat started licking its hind paws. Trials were ended by quick removal of rats from the hot plate surface once a reaction is observed or after a 20-s cut-off time if no reaction was observed. The number of male and female $(\mathrm{M} / \mathrm{F})$ rats per treatment group were as follows: dFBr $5 \mathrm{mg} / \mathrm{kg}$ (4/4), dFBr $10 \mathrm{mg} / \mathrm{kg}$ (4/4), dFBr $20 \mathrm{mg} / \mathrm{kg}$ (4/4), CMPI $2 \mathrm{mg} / \mathrm{kg}$ (6/6), CMPI 5 mg/kg (6/6), CMPI $10 \mathrm{mg} / \mathrm{kg}$ (6/6), CMPI $20 \mathrm{mg} / \mathrm{kg}$ (6 males), nicotine $0.5 \mathrm{mg} / \mathrm{kg}$ (4/4), nicotine $0.5 \mathrm{mg} / \mathrm{kg}+\mathrm{dFBr} 5 \mathrm{mg} / \mathrm{kg}(4 / 4)$, and nicotine $0.5 \mathrm{mg} / \mathrm{kg}+\mathrm{dFBr} 10 \mathrm{mg} / \mathrm{kg}$ (4/4).

\subsubsection{Tail Flick Test}

The tail flick test was performed using the Tail Flick Analgesia Meter (IITC Inc.) Rats were held in the apparatus with the rat tail positioned under an infrared beam, focused on an area of $4 \times 6 \mathrm{~mm}$ as a heat source. Rat reaction time (latency to acute thermal pain in seconds) was recorded using a built-in sensor, as time elapsed after placing the tail under the infrared beam until the rat sensed stimulation and moved its tail away from the heat source. The trials ended by stopping the heat source once the built-in sensor detected the tail flick or after a 10-s cut-off time if the animal showed no tail flick response. The number of male and female $(\mathrm{M} / \mathrm{F})$ rats per treatment group were as follows: $\mathrm{dFBr}$ 5 mg/kg (8/8), dFBr 10 mg/kg (8/8), dFBr 20 mg/kg (4/4), CMPI 2 mg/kg (6/6), CMPI 5 mg/kg (6/6), CMPI $10 \mathrm{mg} / \mathrm{kg}$ (6/6), CMPI $20 \mathrm{mg} / \mathrm{kg}$ (6 males), nicotine $0.5 \mathrm{mg} / \mathrm{kg}$ (8/8), nicotine $0.5 \mathrm{mg} / \mathrm{kg}+\mathrm{dFBr} 5$ $\mathrm{mg} / \mathrm{kg}(4 / 4)$, and nicotine $0.5 \mathrm{mg} / \mathrm{kg}+\mathrm{dFBr} 10 \mathrm{mg} / \mathrm{kg}(4 / 6)$. 


\subsection{Data Analyses}

Data analyses were performed using Excel 2010 (Microsoft Corporation) and the GraphPad Prism software, version 8.4.2 (GraphPad Software, Inc., La Jolla, CA). Latencies to acute thermal nociceptive stimulus recorded in hot plate and tail flick tests were converted to the percentage of maximum possible effect (\%MPE), using Equations (1) and (2), respectively.

$$
\begin{aligned}
& \% \mathrm{MPE}=[(\mathrm{TL}-\mathrm{CL}) /(20-\mathrm{CL}) \times 100] \\
& \% \mathrm{MPE}=[(\mathrm{TL}-\mathrm{CL}) /(10-\mathrm{CL}) \times 100]
\end{aligned}
$$

where TL is the latency at the specified time after treatment and CL is the baseline control latency recorded before treatment. Data were plotted in figures as mean \%MPE \pm SD and analyzed for statistical significance using two-way ANOVA with Holm-Sidak's multiple comparisons test (GraphPad Prism software). Statistical differences ( $\mathrm{p}$-values $<0.05$ ) of drug treatment versus vehicle group, when present, are indicated in figures with asterisks as ${ }^{*}=p<0.05,{ }^{* *}=p<0.01,{ }^{* * *}=p<0.001$, and ${ }^{* * * *}=p<0.0001$. Significant differences of among drug treatments, when present, are indicated in figures with hashtag symbols as \# $=p<0.05$, \#\# $=p<0.01$, \#\#\# = p<0.001, \#\#\# = p $<0.0001$.

Author Contributions: Conceptualization, methodology, and resources, A.K.H. and M.I.D.; investigation and analyses, F.D., K.R., M.V., and K.M.; writing—original draft preparation, review, and editing, F.D., A.K.H., L.S.A., and M.I.D. All authors have read and agreed to the published version of the manuscript.

Funding: This research received no external funding.

Acknowledgments: We would like to thank Jennifer Santos from the Texas A\&M College of Pharmacy vivarium for her indispensable help throughout these studies.

Conflicts of Interest: The authors declare no conflict of interest.

\section{References}

1. Dineley, K.T.; Pandya, A.A.; Yakel, J.L. Nicotinic ACh receptors as therapeutic targets in CNS disorders. Trends Pharmacol. Sci. 2015, 36, 96-108. [CrossRef] [PubMed]

2. Zoli, M.; Pistillo, F.; Gotti, C. Diversity of native nicotinic receptor subtypes in mammalian brain. Neuropharmacology 2015, 96, 302-311. [CrossRef] [PubMed]

3. DeDominicis, K.E.; Sahibzada, N.; Olson, T.T.; Xiao, Y.; Wolfe, B.B.; Kellar, K.J.; Yasuda, R.P. The (alpha4)3(beta2)2 Stoichiometry of the Nicotinic Acetylcholine Receptor Predominates in the Rat Motor Cortex. Mol. Pharmacol. 2017, 92, 327-337. [CrossRef] [PubMed]

4. Nirogi, R.; Goura, V.; Abraham, R.; Jayarajan, P. alpha4beta2* neuronal nicotinic receptor ligands (agonist, partial agonist and positive allosteric modulators) as therapeutic prospects for pain. Eur. J. Pharmacol. 2013, 712, 22-29. [CrossRef]

5. Ueda, M.; Iida, Y.; Tominaga, A.; Yoneyama, T.; Ogawa, M.; Magata, Y.; Nishimura, H.; Kuge, Y.; Saji, H. Nicotinic acetylcholine receptors expressed in the ventralposterolateral thalamic nucleus play an important role in anti-allodynic effects. Br. J. Pharmacol. 2010, 159, 1201-1210. [CrossRef]

6. Umana, I.C.; Daniele, C.A.; McGehee, D.S. Neuronal nicotinic receptors as analgesic targets: it's a winding road. Biochem. Pharmacol. 2013, 86, 1208-1214. [CrossRef]

7. Decker, M.W.; Rueter, L.E.; Bitner, R.S. Nicotinic acetylcholine receptor agonists: a potential new class of analgesics. Curr. Top. Med. Chem. 2004, 4, 369-384. [CrossRef]

8. Hurst, R.; Rollema, H.; Bertrand, D. Nicotinic acetylcholine receptors: from basic science to therapeutics. Pharmacol. Ther. 2013, 137, 22-54. [CrossRef]

9. Damaj, M.I.; Freitas, K.; Bagdas, D.; Flood, P. Nicotinic Receptors as Targets for Novel Analgesics and Anti-inflammatory Drugs. Recept. Ser. 2014, 26, 239-254. [CrossRef]

10. Bannon, A.W.; Decker, M.W.; Holladay, M.W.; Curzon, P.; Donnelly-Roberts, D.; Puttfarcken, P.S.; Bitner, R.S.; Diaz, A.; Dickenson, A.H.; Porsolt, R.D.; et al. Broad-spectrum, non-opioid analgesic activity by selective modulation of neuronal nicotinic acetylcholine receptors. Science 1998, 279, 77-81. [CrossRef] 
11. Marubio, L.M.; del Mar Arroyo-Jimenez, M.; Cordero-Erausquin, M.; Lena, C.; Le Novere, N.; de Kerchove d'Exaerde, A.; Huchet, M.; Damaj, M.I.; Changeux, J.P. Reduced antinociception in mice lacking neuronal nicotinic receptor subunits. Nature 1999, 398, 805-810. [CrossRef] [PubMed]

12. Kesingland, A.C.; Gentry, C.T.; Panesar, M.S.; Bowes, M.A.; Vernier, J.M.; Cube, R.; Walker, K.; Urban, L. Analgesic profile of the nicotinic acetylcholine receptor agonists, (+)-epibatidine and ABT-594 in models of persistent inflammatory and neuropathic pain. Pain 2000, 86, 113-118. [CrossRef]

13. Lynch, J.J., 3rd; Wade, C.L.; Mikusa, J.P.; Decker, M.W.; Honore, P. ABT-594 (a nicotinic acetylcholine agonist): anti-allodynia in a rat chemotherapy-induced pain model. Eur. J. Pharmacol. 2005, 509, 43-48. [CrossRef] [PubMed]

14. Jain, K.K. Modulators of nicotinic acetylcholine receptors as analgesics. Curr. Opin. Investig. Drugs 2004, 5, 76-81.

15. Lee, C.H.; Zhu, C.; Malysz, J.; Campbell, T.; Shaughnessy, T.; Honore, P.; Polakowski, J.; Gopalakrishnan, M. alpha4beta2 neuronal nicotinic receptor positive allosteric modulation: an approach for improving the therapeutic index of alpha4beta2 nAChR agonists in pain. Biochem. Pharmacol. 2011, 82, 959-966. [CrossRef]

16. Williams, D.K.; Wang, J.; Papke, R.L. Positive allosteric modulators as an approach to nicotinic acetylcholine receptor-targeted therapeutics: advantages and limitations. Biochem. Pharmacol. 2011, 82, 915-930. [CrossRef]

17. Rode, F.; Munro, G.; Holst, D.; Nielsen, E.O.; Troelsen, K.B.; Timmermann, D.B.; Ronn, L.C.; Grunnet, M. Positive allosteric modulation of alpha4beta2 nAChR agonist induced behaviour. Brain Res. 2012, 1458, 67-75. [CrossRef]

18. Uteshev, V.V. Allosteric Modulation of Nicotinic Acetylcholine Receptors: The Concept and Therapeutic Trends. Curr. Pharm. Des. 2016, 22, 1986-1997. [CrossRef]

19. Mohamed, T.S.; Jayakar, S.S.; Hamouda, A.K. Orthosteric and Allosteric Ligands of Nicotinic Acetylcholine Receptors for Smoking Cessation. Front Mol. Neurosci. 2015, 8, 71. [CrossRef]

20. Wilkerson, J.L.; Deba, F.; Crowley, M.L.; Hamouda, A.K.; McMahon, L.R. Advances in the In vitro and In vivo pharmacology of Alpha4beta2 nicotinic receptor positive allosteric modulators. Neuropharmacology 2020, 168, 108008. [CrossRef]

21. Manetti, D.; Bellucci, C.; Chiaramonte, N.; Dei, S.; Teodori, E.; Romanelli, M.N. Designing selective modulators for the nicotinic receptor subtypes: challenges and opportunities. Future Med. Chem. 2018, 10, 433-459. [CrossRef]

22. Pandya, A.; Yakel, J.L. Allosteric modulators of the alpha4beta2 subtype of neuronal nicotinic acetylcholine receptors. Biochem. Pharmacol. 2011, 82, 952-958. [CrossRef]

23. Sala, F.; Mulet, J.; Reddy, K.P.; Bernal, J.A.; Wikman, P.; Valor, L.M.; Peters, L.; Konig, G.M.; Criado, M.; Sala, S. Potentiation of human alpha4beta2 neuronal nicotinic receptors by a Flustra foliacea metabolite. Neurosci. Lett. 2005, 373, 144-149. [CrossRef] [PubMed]

24. Albrecht, B.K.; Berry, V.; Boezio, A.A.; Cao, L.; Clarkin, K.; Guo, W.; Harmange, J.C.; Hierl, M.; Huang, L.; Janosky, B.; et al. Discovery and optimization of substituted piperidines as potent, selective, CNS-penetrant alpha4beta2 nicotinic acetylcholine receptor potentiators. Bioorg. Med. Chem. Lett. 2008, 18, 5209-5212. [CrossRef] [PubMed]

25. Olsen, J.A.; Ahring, P.K.; Kastrup, J.S.; Gajhede, M.; Balle, T. Structural and functional studies of the modulator NS9283 reveal agonist-like mechanism of action at alpha4beta2 nicotinic acetylcholine receptors. J. Biol. Chem. 2014, 289, 24911-24921. [CrossRef] [PubMed]

26. Zhu, C.Z.; Chin, C.L.; Rustay, N.R.; Zhong, C.; Mikusa, J.; Chandran, P.; Salyers, A.; Gomez, E.; Simler, G.; Lewis, L.G.; et al. Potentiation of analgesic efficacy but not side effects: co-administration of an alpha4beta2 neuronal nicotinic acetylcholine receptor agonist and its positive allosteric modulator in experimental models of pain in rats. Biochem. Pharmacol. 2011, 82, 967-976. [CrossRef] [PubMed]

27. Bagdas, D.; Ergun, D.; Jackson, A.; Toma, W.; Schulte, M.K.; Damaj, M.I. Allosteric modulation of alpha4beta2* nicotinic acetylcholine receptors: Desformylflustrabromine potentiates antiallodynic response of nicotine in a mouse model of neuropathic pain. Eur. J. Pain 2018, 22, 84-93. [CrossRef]

28. Weggel, L.A.; Pandya, A.A. Acute Administration of Desformylflustrabromine Relieves Chemically Induced Pain in CD-1 Mice. Molecules 2019, 24. [CrossRef]

29. Gotti, C.; Clementi, F.; Fornari, A.; Gaimarri, A.; Guiducci, S.; Manfredi, I.; Moretti, M.; Pedrazzi, P.; Pucci, L.; Zoli, M. Structural and functional diversity of native brain neuronal nicotinic receptors. Biochem. Pharmacol. 2009, 78, 703-711. [CrossRef] 
30. Bertrand, D.; Terry, A.V., Jr. The wonderland of neuronal nicotinic acetylcholine receptors. Biochem. Pharmacol. 2018, 151, 214-225. [CrossRef]

31. Hamouda, A.K.; Deba, F.; Wang, Z.J.; Cohen, J.B. Photolabeling a Nicotinic Acetylcholine Receptor (nAChR) with an (alpha4)3(beta2)2 nAChR-Selective Positive Allosteric Modulator. Mol. Pharmacol. 2016, 89, 575-584. [CrossRef] [PubMed]

32. Wang, Z.J.; Deba, F.; Mohamed, T.S.; Chiara, D.C.; Ramos, K.; Hamouda, A.K. Unraveling amino acid residues critical for allosteric potentiation of (alpha4)3(beta2)2-type nicotinic acetylcholine receptor responses. J. Biol. Chem. 2017, 292, 9988-10001. [CrossRef] [PubMed]

33. Weltzin, M.M.; Schulte, M.K. Desformylflustrabromine Modulates alpha4beta2 Neuronal Nicotinic Acetylcholine Receptor High- and Low-Sensitivity Isoforms at Allosteric Clefts Containing the beta2 Subunit. J. Pharmacol. Exp. Ther. 2015, 354, 184-194. [CrossRef] [PubMed]

34. Deba, F.; Ali, H.I.; Tairu, A.; Ramos, K.; Ali, J.; Hamouda, A.K. LY2087101 and dFBr share transmembrane binding sites in the (alpha4)3(beta2)2 Nicotinic Acetylcholine Receptor. Sci. Rep. 2018, 8, 1249. [CrossRef]

35. AlSharari, S.; Bagdas, D.; Akbarali, H.; Cabral, G.A.; Carroll, F.I.; Damaj, I.; Lichtman, P. Sex Differences and Drug Dose Influence the Role of the alpha-7 Nicotinic Acetylcholine Receptor in the Mouse Dextran Sodium Sulfate-Induced Colitis Model. Am. J. Gastroenterol. 2015, 110, S776. [CrossRef]

36. Liu, X. Positive allosteric modulation of alpha 4 beta 2 nicotinic acetylcholine receptors as a new approach to smoking reduction: evidence from a rat model of nicotine self-administration. Psychopharmacology 2013, 230, 203-213. [CrossRef]

37. Mitra, S.; Mucha, M.; Khatri, S.N.; Glenon, R.; Schulte, M.K.; Bult-Ito, A. Attenuation of Compulsive-Like Behavior Through Positive Allosteric Modulation of alpha4beta2 Nicotinic Acetylcholine Receptors in Non-Induced Compulsive-Like Mice. Front Behav. Neurosci. 2016, 10, 244. [CrossRef]

38. Moerke, M.J.; de Moura, F.B.; Koek, W.; McMahon, L.R. Effects of nicotine in combination with drugs described as positive allosteric nicotinic acetylcholine receptor modulators in vitro: discriminative stimulus and hypothermic effects in mice. Eur. J. Pharmacol. 2016, 786, 169-178. [CrossRef]

39. Hamouda, A.K.; Jackson, A.; Bagdas, D.; Imad Damaj, M. Reversal of Nicotine Withdrawal Signs Through Positive Allosteric Modulation of alpha4beta2 Nicotinic Acetylcholine Receptors in Male Mice. Nicotine Tob. Res. 2018, 20, 903-907. [CrossRef]

40. Dennis, S.G.; Melzack, R.; Gutman, S.; Boucher, F. Pain modulation by adrenergic agents and morphine as measured by three pain tests. Life Sci. 1980, 26, 1247-1259. [CrossRef]

41. Langerman, L.; Zakowski, M.I.; Piskoun, B.; Grant, G.J. Hot plate versus tail flick: evaluation of acute tolerance to continuous morphine infusion in the rat model. J. Pharmacol. Toxicol. Methods 1995, 34, $23-27$. [CrossRef]

42. Hamouda, A.K.; Wang, Z.J.; Stewart, D.S.; Jain, A.D.; Glennon, R.A.; Cohen, J.B. Desformylflustrabromine $(\mathrm{dFBr})$ and $[3 \mathrm{H}] \mathrm{dFBr}-$ Labeled Binding Sites in a Nicotinic Acetylcholine Receptor. Mol. Pharmacol. 2015, 88, 1-11. [CrossRef] [PubMed]

43. Alcaino, C.; Musgaard, M.; Minguez, T.; Mazzaferro, S.; Faundez, M.; Iturriaga-Vasquez, P.; Biggin, P.C.; Bermudez, I. Role of the Cys Loop and Transmembrane Domain in the Allosteric Modulation of alpha4beta2 Nicotinic Acetylcholine Receptors. J. Biol. Chem. 2017, 292, 551-562. [CrossRef]

44. Freitas, K.; Negus, S.S.; Carroll, F.I.; Damaj, M.I. In vivo pharmacological interactions between a type II positive allosteric modulator of alpha7 nicotinic ACh receptors and nicotinic agonists in a murine tonic pain model. Br. J. Pharmacol. 2013, 169, 567-579. [CrossRef] [PubMed]

(C) 2020 by the authors. Licensee MDPI, Basel, Switzerland. This article is an open access article distributed under the terms and conditions of the Creative Commons Attribution (CC BY) license (http://creativecommons.org/licenses/by/4.0/). 